\title{
Stem-cell-based therapies to enhance peripheral nerve regeneration
}

\author{
Carrie A. Kubiak MD $\quad$ ～Joey Grochmal MD, PhD ${ }^{2} \quad$ Theodore A. Kung MD \\ Paul S. Cederna MD ${ }^{1,3}$ | Rajiv Midha MD, MSc ${ }^{2}$ | Stephen W.P. Kemp PhD
}

\author{
${ }^{1}$ Department of Surgery, Section of Plastic and \\ Reconstructive Surgery, University of \\ Michigan, Ann Arbor, Michigan \\ ${ }^{2}$ Department of Clinical Neurosciences and \\ Hotchkiss Brain Institute, Cumming School of \\ Medicine, University of Calgary, Calgary, \\ Alberta, Canada \\ ${ }^{3}$ Department of Biomedical Engineering, \\ University of Michigan, Ann Arbor, Michigan \\ Correspondence \\ Stephen W.P. Kemp, Department of \\ Biomedical Engineering, University of \\ Michigan, 1150 West Medical Center Drive, \\ MSRB II, A570, Ann Arbor, MI 48109-5456. \\ Email: swpkemp@med.umich.edu
}

\begin{abstract}
Peripheral nerve injury remains a major cause of morbidity in trauma patients. Despite advances in microsurgical techniques and improved understanding of nerve regeneration, obtaining satisfactory outcomes after peripheral nerve injury remains a difficult clinical problem. There is a growing body of evidence in preclinical animal studies demonstrating the supportive role of stem cells in peripheral nerve regeneration after injury. The characteristics of both mesoderm-derived and ectoderm-derived stem cell types and their role in peripheral nerve regeneration are discussed, specifically focusing on the presentation of both foundational laboratory studies and translational applications. The current state of clinical translation is presented, with an emphasis on both ethical considerations of using stems cells in humans and current governmental regulatory policies. Current advancements in cell-based therapies represent a promising future with regard to supporting nerve regeneration and achieving significant functional recovery after debilitating nerve injuries.
\end{abstract}

\section{KEYWORDS}

cellular therapy, peripheral nerve injury, nerve regeneration, stem cell, Schwann cells, neuroregeneration

\section{1 | INTRODUCTION}

Peripheral nerve injury remains a major cause of morbidity in trauma patients. ${ }^{1}$ Despite advances in microsurgical techniques and improved understanding of nerve regeneration, obtaining satisfactory outcomes after peripheral nerve injury remains a serious clinical problem..$^{2-4}$

\footnotetext{
Abbreviations: AD, Alzheimer disease; ADSC, adipose-derived stem cell; ALS, amyotrophic lateral sclerosis; AMSC, amniotic mesenchymal stromal cell; BFP, blue fluorescent protein; BDNF, brain-derived neurotrophic factor; BMSC, bone marrow stromal cell; CNTF, ciliary neurotrophic factor; DMD, Duchenne muscular dystrophy; DPSC, dental pulp stem cell; DRG, dorsal root ganglion; GDNF, glial-cell-line-derived neurotrophic factor; GFP, green fluorescent protein; GGF, glial-growth-like factor; HAP, hair follicle-associated pluripotent cell; HGF, hepatocyte growth factor; hESC, human embryonic-derived support cell; hUCBDSC, human umbilical cord blood-derived stem cell; IGF, insulin-like growth factor; MS, multiple sclerosis; NCC, neural crest stem cell; NGF, nerve growth factor; OEC, olfactory ensheathing cell; RGC, retinal ganglion cell; SC, Schwann cell; SFI, sciatic functional index; SkSC, skeletal muscle-derived stem cell; SKP, skin-derived precursor cell; TrkB, tyrosine kinase $\mathrm{B}$; VEGF, vascular endothelial growth factor.

C.A.K. and J.G. contributed equally to this work.
}

Unfortunately, a large proportion of patients with severe peripheral nerve injuries fail to recover normal function., ${ }^{5,6}$ Even after the most optimal surgical situation of direct nerve repair, return of motor and sensory function is slow and often incomplete..$^{7-9}$

The regeneration of damaged peripheral nerves occurs though a complex process in which Schwann cells (SCs) play a crucial role. ${ }^{10} \mathrm{After}$ axonal injury, SCs proliferate, phagocytose debris, and recruit macrophages ${ }^{11}$ to help establish the optimal regenerative milieu. ${ }^{12}$ These cells further aid in axonal regrowth by synthesizing neurotrophic factors, ${ }^{13-15}$ producing both extracellular matrix and cell-adhesion molecules, ${ }^{16}$ and providing physical guidance to regenerating axons. ${ }^{17,18} \mathrm{SC}$-based therapies have been successfully utilized in preclinical animal models to enhance nerve regeneration. ${ }^{19-22}$ However, due to the invasive nature of SC harvest ${ }^{23}$ and the difficulty of cell expansion in vitro, ${ }^{24}$ there remain significant barriers to clinical use. ${ }^{25}$

In light of the practical limitations associated with $\mathrm{SC}$, there has been growing enthusiasm for the use of both precursor and stem cell- 
based therapies (we use the term "stem cell" throughout this review to maintain consistency while recognizing that few of the cell sources mentioned are true stem cells) for peripheral nerve regeneration. ${ }^{26-29}$ We are also cognizant of the fact that embryonic stem cells generally have a higher regenerative capacity and are less lineage committed than adult precursor and/or stem cells. ${ }^{30,31}$ There is a growing body of evidence in preclinical animal studies showing that stem cells play a positive role in the regeneration of peripheral nerves after injury. ${ }^{32-37}$ These effects are thought to be based on the ability of transplanted stem cells to promote regeneration by cell differentiation into tissuespecific cell types, ${ }^{38-40}$ signaling through cell-to-cell contact, and/or sustained release of neurotrophic factors. ${ }^{27,41,42} \mathrm{~A}$ number of stem cell types with varying phenotypic and gene expression profiles have been investigated. In this review we summarize the literature supporting the utilization of various stem cell types that have been employed to enhance peripheral nerve regeneration. A detailed list of the stem cell types discussed is presented in Table 1 . We review the foundational laboratory studies for each type and then focus on translational works using human-derived cells in animals. If available, the current use of these cells in humans for the treatment of peripheral nerve conditions is also highlighted.

\section{2 | BONE MARROW STROMAL STEM CELLS}

One of the most comprehensively studied cell types with respect to peripheral nerve regenerative potential is the bone marrow stromal stem cell (BMSC). These multipotent cells may differentiate into mesenchymal lineages but can also be persuaded to adopt an SC phenotype in vitro. ${ }^{26}$ However, their eventual fate in vivo may not robustly retain this differentiation. ${ }^{43,44}$

BMSCs effectively produce and secrete numerous neurotrophins (eg, nerve growth factor [NGF], brain-derived neurotrophic factor [BDNF], glial-cell-line-derived neurotrophic factor [GDNF], ciliary neurotrophic factor [CNTF]) in peripheral nerve repair and have been previously shown to enhance regeneration. ${ }^{45,46}$ Chen et al convincingly showed improved walking track scores, wet muscle weights, and increased axonal counts in a 15-mm-gap sciatic transection model ${ }^{45}$ using BMSC therapy. These cells have also been tested (and found efficacious) as supplements to nerve scaffolds using inside-out arterial grafts, ${ }^{47}$ decellularized nerve grafts, ${ }^{48-51}$ and veins. ${ }^{52}$ One study showed a relative inferiority of BMSCs when directly compared with SCs for electrophysiological recovery of a sciatic transection/silicone tube model, although functionally the groups performed at equivalent levels. ${ }^{53}$ BMSCs have also been studied in larger animal models of long-gap nerve regeneration, including rabbits ${ }^{54}$ and nonhuman primates, ${ }^{55}$ and in the latter demonstrated efficacy on par with both SCs and allografts.

A further notable observation is the ability of BMSCs to "home in" to injured targets, where they have demonstrated this ability in central nervous system animal injury models when administered intravenously. ${ }^{56}$ Although BMSCs are yet to be used in humans, the practicality of an effective systemic stem cell therapy makes these cells a prime candidate for translational study.

\section{3 | ADIPOSE-DERIVED STEM CELLS}

Originally described by Zuk et al, adipose-derived stem cells (ADSCs) present a potential adjunct to improve nerve repair and are derived from adipose tissue, which in turn is derived from embryonic mesoderm. ${ }^{57,58}$ However, they can be effectively differentiated along ectodermal lines, with SC-like ADSCs, first described in 2007 by Kingham and colleagues. $^{38}$ Numerous studies have focused on neuroregenerative effects of adipose tissue using purified, cultured, differentiated, or dedifferentiated adipose-derived tissues. ${ }^{59-61}$ ADSCs have also been extensively investigated for use in peripheral nerve regeneration, with promising results. They produce mRNA for the growth factors BDNF, glial-growth-like factor (GGF), neurogulin-1 (NRG-1), vascular endothelial growth factor (VEGF), hepatocyte growth factor (HGF), and insulin-like growth factor (IGF) on par or greater than $\mathrm{SCs}$ in culture. ${ }^{41}$ ADSCs support a robust neurite response $^{38}$ and myelinate dorsal root ganglion (DRG) neurites in vitro. ${ }^{62}$ When used in animal models, they may be superior to both $\mathrm{SCs}$ and mesenchymal cells for regeneration through a fibrin conduit. ${ }^{63}$ They have also demonstrated efficacy in improving recovery in both acute and chronic sciatic denervation injury paradigms in rodents. $^{62,64}$

One benefit of ADSCs for clinical translation is the relative abundance of adipose tissue for harvest. In this regard, human adiposederived mesenchymal cells obtained from abdominal fat was shown to improve recovery metrics when injected into a murine sciatic crush model, as demonstrated by sciatic functional index (SFI) and walking track analysis. Remarkably, in the study, these cells were injected systemically (intravenously) and were found to localize at the area of injury. ${ }^{65}$ As a counterpoint, it would seem that mesenchymal cells derived from human adipose tissue may not maintain their SC-like phenotype for long when withdrawn from the permissive in-vitro cocktail of mitogens and growth factors, as recently demonstrated by Faroni et al. ${ }^{66}$ Adult adipose mesenchymal cells also have known limitations in terms of senescence and donor-age-dependent efficacy, making their specific clinical indications the subject of future research.

\section{4 | AMNIOTIC MESENCHYMAL STROMAL CELLS}

Amniotic mesenchymal stromal cells (AMSCs) are derived from the avascular amniotic mesoderm, and are relatively non-immunogenic cells. ${ }^{67-70}$ Because of this, their membrane has been investigated as a cellular scaffold both in vivo ${ }^{71}$ and ex vivo. ${ }^{67}$ Recently, the in-toto amniotic membrane has been differentiated toward an SC phenotype and proposed as a scaffold alternative to autograft repair. ${ }^{72}$ AMSCs have been compared with 


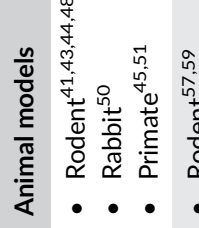

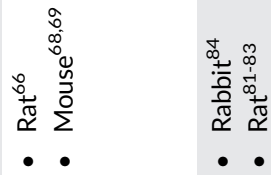

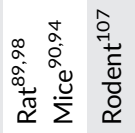

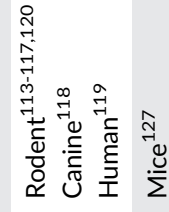

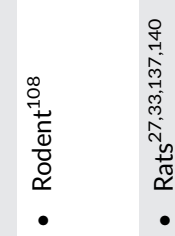

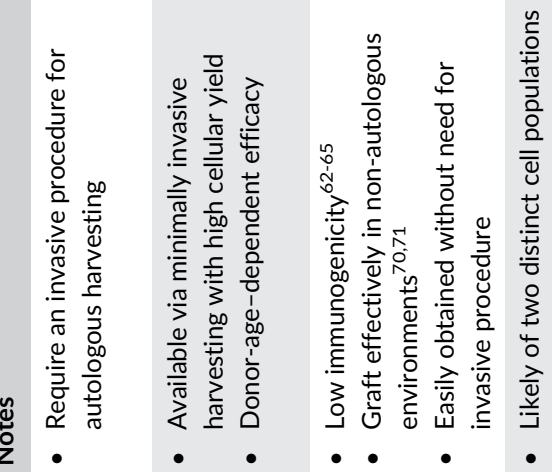

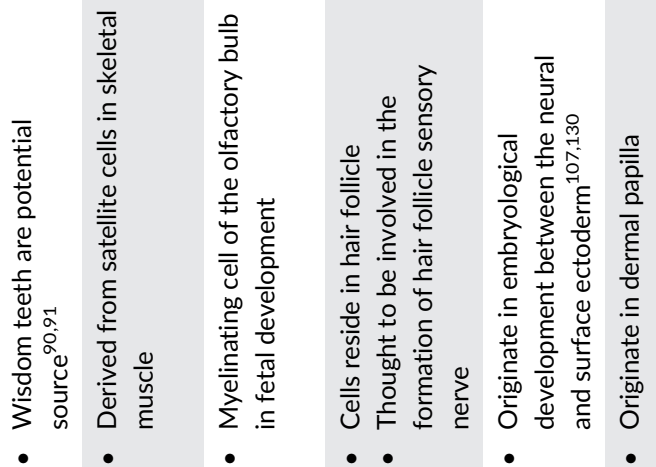
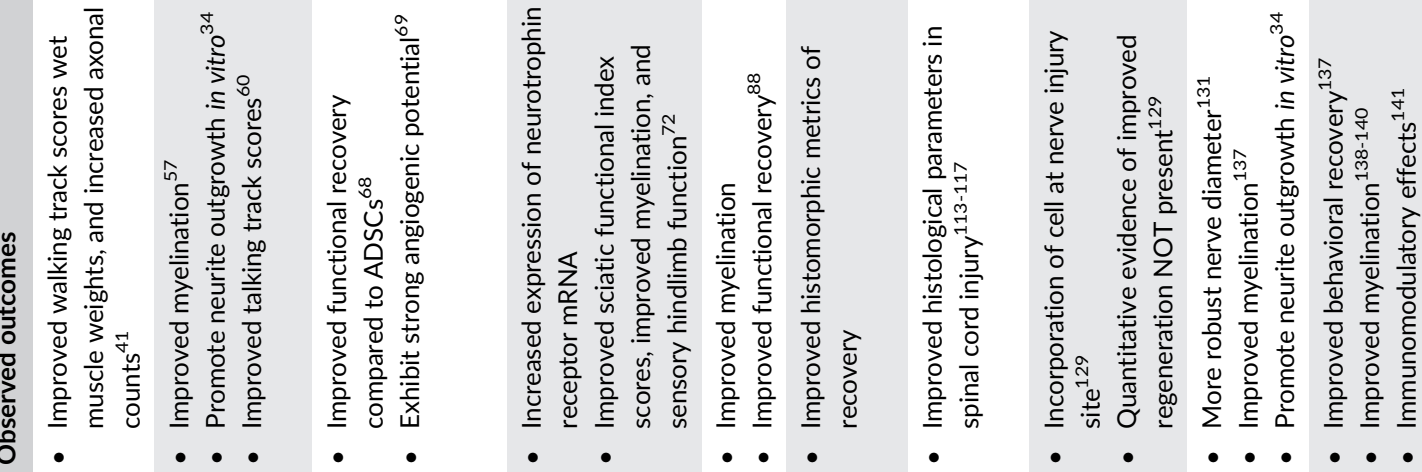

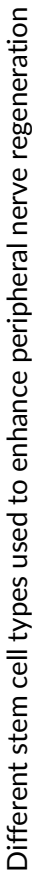
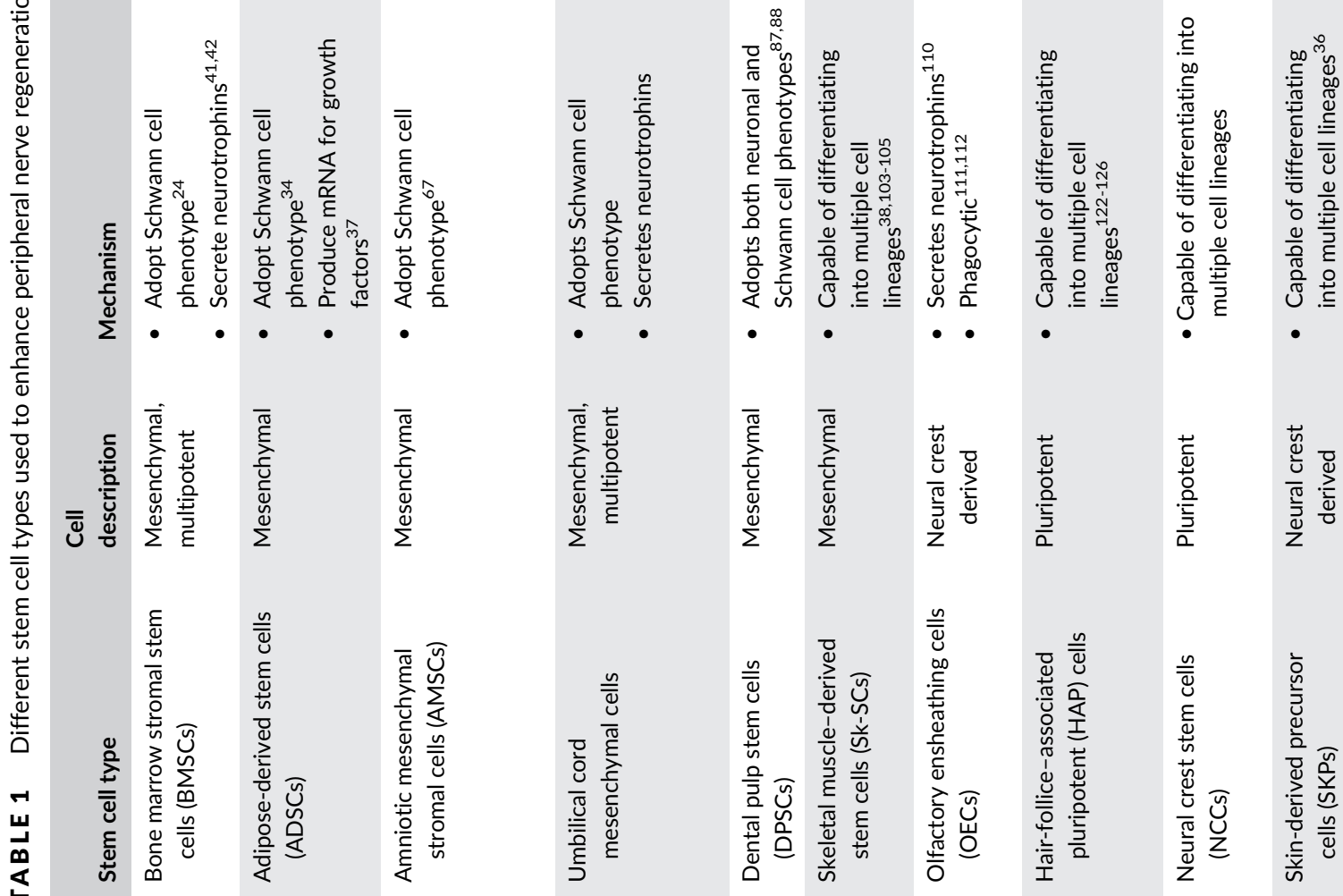
ADSCs in a sciatic nerve crush model, and were found to be better at improving electrophysiological and functional recovery at 4 weeks postinjury. ${ }^{73}$ Interestingly, the AMSCs markedly improved the overall perfusion vascularity of the injured sciatic nerve distal to the crush (Figure 1), in keeping with their known angiogenic profile. ${ }^{74}$

AMSCs are an interesting candidate for human transplantation experiments, with their demonstrated ability to graft effectively into non-autologous environments. ${ }^{75,76}$ Such biocompatibility may enable allograft cell banks to be developed for immediate human use, without the need for posttransplant immunosuppression.

\section{5 | UMBILICAL CORD MESENCHYMAL CELLS}

The umbilical cord is a valuable source for mesenchymal stem cells, both from the Wharton jelly ${ }^{77,78}$ and umbilical cord blood. ${ }^{79-83}$ These are multipotent cells that are likely of two distinct populations: one with a propensity to differentiate into neuronal ectodermal phenotypes, and another with a mesodermal lineage production. ${ }^{79}$ These cells have been previously shown to express pluripotent stem cell markers, such as Oct4, Nanog, Sox2, ABCG2, and the neuroectodermal marker nestin. ${ }^{79}$ There are several potential advantages to the use of these cells, including: 1) ease of accessibility; 2) the fact that they are immunologically inert; 3 ) their use bears no ethical
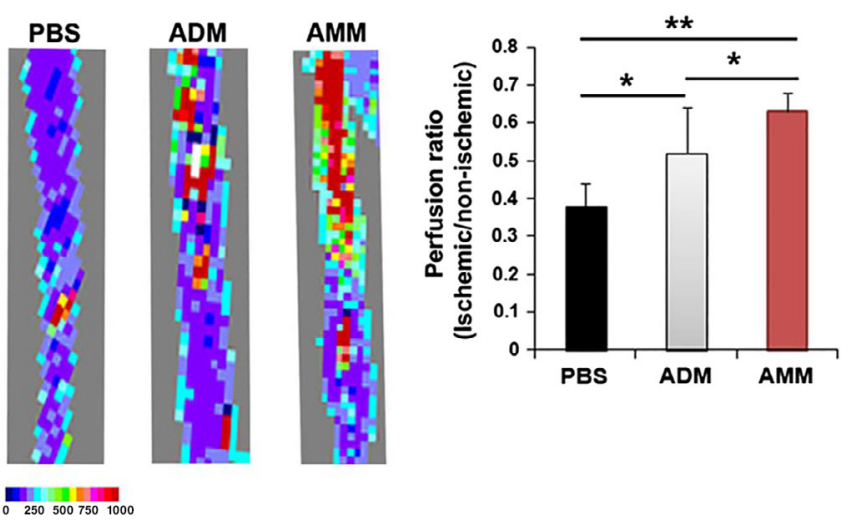

FIGURE 1 Transplantation of AMMs augments blood perfusion. A, Representative images of blood perfusion in the sciatic nerve. Blood perfusion was performed 4 weeks after the initial operation with LDPI (Moor Instrument, Wilmington, Delaware). B, Quantitative analysis using LDPI. AMMs significantly improved blood perfusion compared with ADM stem cells and PBS. LDPI of blood was done 4 weeks after the operation, as described elsewhere. ${ }^{14}$ Briefly, the mice were anesthetized and placed on a heating blanket to maintain a constant temperature. The nerves were exposed by using blunt dissection and scalpel incision. The blood flow in the sciatic nerve was examined using LDPI. ADM, adipose-derived mesenchymal; AMM, amniotic membrane-derived mesenchymal stem cell; LDPI, laser Doppler perfusion imaging; PBS, phosphate-buffered saline. $* * P<.01 ; * P<.05$ ( $\mathrm{n}=9$ per group). Source: Data excerpted from Li et al (2014). ${ }^{73}$ considerations; and 4) they possess a low probability of resulting in graft-vs-host disease. $^{83,84}$

As peripheral nerve regeneration support cells, the therapeutic potential of human umbilical cord blood-derived stem cells (hUCBDSCs) has been investigated in studies of cavernous nerve injury, recurrent laryngeal nerve injury, optic nerve injury, and sciatic nerve injury, ${ }^{85-89}$ all with varying degrees of success. hUCBDSCs were shown to improve recovery from rat sciatic nerve crush injury, with improved SFI over noninjured controls as well as increased expression of both BDNF and tyrosine kinase B (TrkB) receptor mRNA. Wharton jelly-derived umbilical mesenchymal cells also seem to improve recovery from rodent sciatic nerve crush, showing improvements in SFI, myelin histology, and sensory hindlimb function. ${ }^{78}$

\section{6 | DENTAL PULP STEM CELLS}

Thought to be an embryological derivative of the cranial neural crest, ${ }^{39,90}$ human dental pulp houses a progenitor mesenchymal population that easily differentiates into both a neural and SC phenotype in vitro. ${ }^{91-93}$ First described by Gronthos and colleagues in 2000, DPSCs are self-renewing, and express numerous stem cell markers such as CD29, CD90, CD271, nestin, and glial fibrillary acidic protein (GFAP), and do not express hematopoietic markers. ${ }^{94-97}$ These cells have been shown to be able to differentiate into numerous tissue types, including neurons, ${ }^{98}$ myoctes, ${ }^{99}$ hair follicle cells, ${ }^{100}$ and hepatocytes. ${ }^{101}$ However, research has also shown that these cells are susceptible to cellular senescence, and that they secrete toxic factors to adjacent tissues when they develop this phenotype. ${ }^{102}$

DPSCs were used in experimental models of optic nerve injury, where they have been shown to promote neurotrophin mediated retinal ganglion cell (RGC) survival, and axonal regeneration after optic nerve injury. ${ }^{103}$ When cocultured in vitro with DRG cells, DPSCs displayed increased survival, neuritogenesis, and myelination when compared with undifferentiated DPSC cultures. ${ }^{92,104}$ These cells also demonstrated myelinating capacity and improved functional recovery from rodent sciatic nerve transection. ${ }^{105}$ They have been shown to counterbalance peripheral nerve injury-induced oxidative stress and neuroinflammation. ${ }^{106}$ Interestingly, these cells may have their regenerative effects seen in crush injury enhanced by application of an external pulsed electromagnetic field. ${ }^{107}$ Clinically, wisdom teeth may one day be a potential source of autologous donation for this particular type of stem cell for use in the treatment of peripheral nerve injuries.

\section{7 | SKELETAL MUSCLE-DERIVED STEM CELLS}

Isolated skeletal muscle-derived stem cells (Sk-SCs) obtained from skeletal muscle satellite cells are able to differentiate into multiple lineages, including myogenic, adipogenic, osteoblastic, neuronal, and glial. ${ }^{42,108-110}$ These cells therefore display a clonal productivity somewhere on the spectrum between ectodermal and mesodemeral. ${ }^{111}$ 
In a murine model of a long nerve gap injury using an acellular scaffold, Sk-SC-seeded grafts demonstrated improved histomorphological metrics of recovery vs control grafts. These cells formed SCs as well as cells of both the endo- and perineurial architecture, suggesting that SkSCs may help in forming coordinated regeneration by being able to reconstitute the muscle-nerve-blood vessel unit. ${ }^{112}$ Interestingly, the
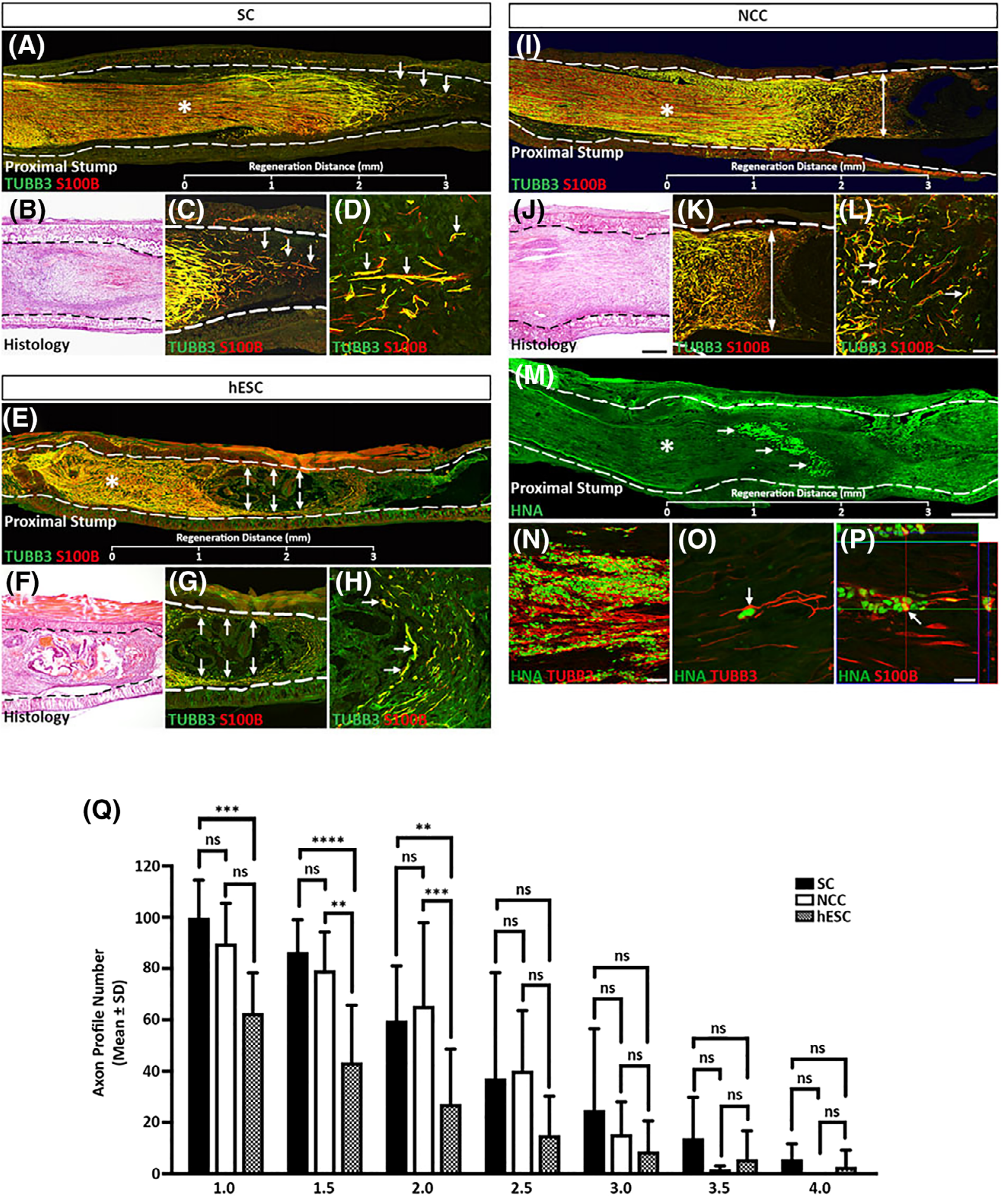

Distance From Proximal Stump (mm)

FIGURE 2 Differentiated NCCs show enhanced in-vivo sciatic nerve regeneration. A-P, Immunohistochemical and histological analyses of longitudinal sections through transplanted biodegradable conduits seeded with control rat Schwann cells (a-d), hESCs (e-h), or differentiated NCCs (i-p). Dashed lines mark the walls of the conduits. Asterisks represent the site of nerve transection and the beginning of the regeneration front. Q, Axon profile numbers beginning $1 \mathrm{~mm}$ distal to the proximal stump. The data represent the mean \pm standard deviation of five independent measurements from each animal and condition. Scale bars: $500 \mu \mathrm{m}$ for a, e, i, and m; $200 \mu \mathrm{m}$ for b, c, f, j, g, k, and n; $50 \mu \mathrm{m}$ for d, h, and I; and $20 \mu \mathrm{m}$ for o and p. hESCs, human embryonic stem cells; HNA, human nuclear antigen; NCC, neural crest cell; SC, Schwann cells. $P$ values are denoted as follows: $\mathrm{ns}=$ not significant; $* * P \leq .01 ; * * * P \leq .001 ; * * * * P \leq .0001$. Source: Data adapted from Jones et al (2018). ${ }^{138}$ 
same research group also used human-derived Sk-SCs in a murine sciatic graft model with similar positive results in both histological parameters as well as metrics of tibial muscle health. ${ }^{113}$

\section{OLFACTORY ENSHEATHING CELLS}

This cell class originates as the myelinating cell of the olfactory bulb in fetal development. ${ }^{114}$ Olfactory ensheathing cells (OECs) have demonstrated an ability to respond to injury by secretion of an extensive array of neurotrophins, ${ }^{115}$ and also act as the primary phagocytic cell of the olfactory bulb, ${ }^{116}$ clearing debris and bacteria alike. ${ }^{117}$

OECs have shown great promise in restoring function and improving histological injury parameters in animal models of spinal cord injury, ${ }^{118-122}$ and they remain one of the few cell types to be utilized experimentally in clinical human spinal cord injury. ${ }^{123,124}$ However, their utility in peripheral nerve injury remains less clear; although they integrate and may improve function after rat sciatic nerve injury, ${ }^{125}$ their efficacy in doing so may not be on par with transplanted SCs. ${ }^{126}$

\section{9 | HAIR FOLLICLE-ASSOCIATED PLURIPOTENT CELLS}

Hair follicle-associated pluripotent (HAP) cells are nestin-expressing cells that reside in the hair follicle and are thought to be intimately involved in the formation of the hair follicle sensory nerve. ${ }^{127}$ They are pluripotent and can differentiate into cells of both glial and neuronal lineage, ${ }^{128}$ as well as smooth muscle myocytes, keratinocytes, and melanocytes. ${ }^{129-131}$ One challenge is that HAP cells remain pluripotent in regenerative models, transforming into both neurons and glia in vivo. ${ }^{132}$ This presents a significant problem for the translatable utility of these cells clinically. It is speculated that the skin-derived precursor (SKP) cell may be one of the early fates of the HAP cell. ${ }^{133}$

Newly regenerated axons from explanted hair follicles are highly enriched in HAP cells in vitro, with their primary in-vivo function thought to be the caretaking of the hair follicle sensory nerve. ${ }^{127}$ One study showed that HAP cells appear to incorporate into the regenerating microenvironment of a sciatic nerve transection injury, although robust quantitative evidence of improved regeneration was not present. ${ }^{134}$ Further investigation into seeding HAP cells in polyvinylidene fluoride membranes for a sciatic gap injury also demonstrated good incorporation at the injury site. However, there was no additional evidence of functional benefit according to walking track analysis when compared with controls. ${ }^{132}$

\section{NEURAL CREST STEM CELLS}

Neural crest stem cells (NCCs) originate in embryological development as migratory progenitors that initially appear between the neural and surface ectoderm at approximately embryologic day $8{ }^{112,135}$ These cells maintain their multipotency during and after migration. ${ }^{136}$ NCCs have been identified in both embryonic and postnatal adult tissues, including bone marrow, DRG, carotid body, cornea, gut, heart, sciatic nerve, and skin. ${ }^{137}$ NCCs are a promising strategic intervention for nerve repair given that they are the parent population to several peripheral nervous system lineages, including immature SC-like cells. ${ }^{138}$

NCCs that were differentiated from human embryonic-derived support cells (hESCs) were shown to incorporate well into a murine model of sciatic nerve repair and convincingly demonstrate histological benefit over nontreated nerves, with more robust nerve diameter and myelination demonstrated in cell treatment groups. ${ }^{139}$ Interestingly, medium from differentiated NSCs enhanced outgrowth of DRG neurites in vitro, while at the same time convincingly demonstrated improved regeneration of $\mathrm{NCC} / \mathrm{scaffold}$-assisted sciatic nerve repair on par with an SC-assisted cohort (Figure 2). ${ }^{138}$ Of note, these cells were derived from hESCs, suggesting their efficacy in rodent models of peripheral nerve regeneration.

\section{1 | SKIN-DERIVED PRECURSOR CELLS}

First isolated and characterized by Toma et al, ${ }^{140}$ skin-derived precursor cells (SKPs) originate in dermal papilla and readily differentiate into
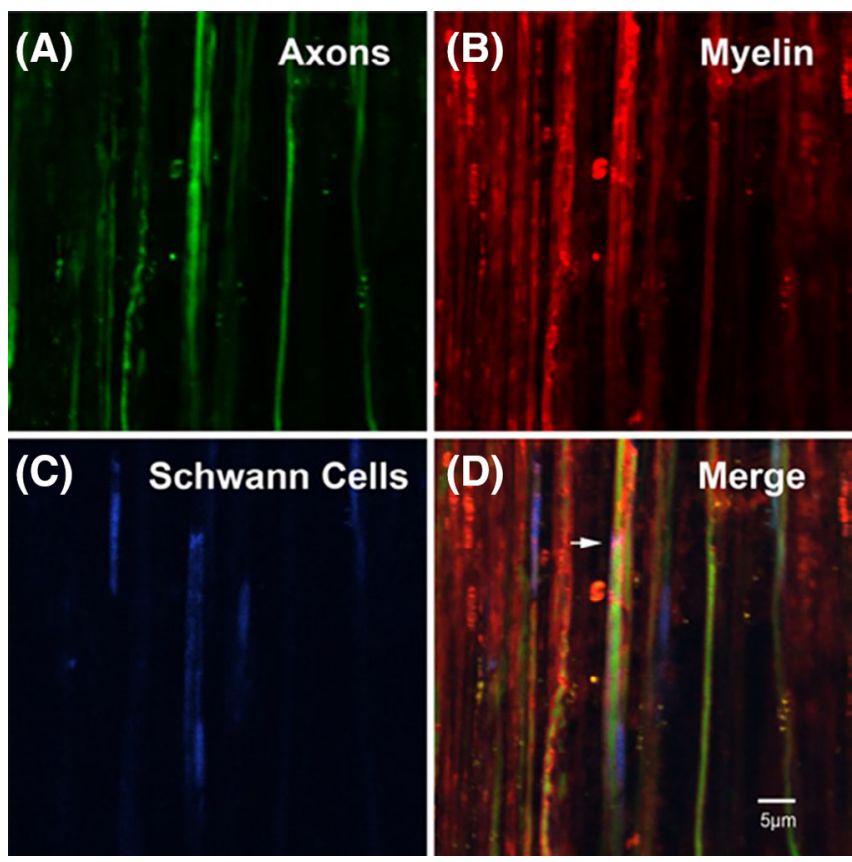

FIGURE 3 Lentiviral enhanced BFP SCs injected into Thy-1 GFP rats that underwent doxorubicin-induced focal demyelination of the tibial nerve. High-magnification intravital images of BFP-positive SKPSC myelination is shown, including a three-channel unmixed spectral image demonstrating live in-vivo myelination by SKP-SCs 27 days after doxorubicin tibial nerve injury, 19 days after cell injection. A, GFP axons. B, Nile red myelin. C, BFP Schwann cells. D, Merged image, where the arrow indicates a probable node of Ranvier, as evidenced by BFP-positive cytoplasm crossing the axon, likely in loosely packed paranodal myelin. BFP, blue fluorescent protein; SC, Schwann cells; SKP-SC, skin-derived precursor Schwann cell. Source: Data adapted from Grochmal et al (2018). ${ }^{144}$ 
neurons and glia, as well as smooth muscle cells. ${ }^{40}$ Early work demonstrated the efficacy of the SKP in assuming an SC lineage (SKP-SC) when exposed to the proper mitogens, ${ }^{40}$ and extensive work followed to investigate the role of the SKP-SC in peripheral nerve repair. ${ }^{27,141-143}$ SKP-SCs have proven beneficial in sciatic nerve repair with acellular nerve grafts, ${ }^{142}$ and a delayed cross-reinnervation paradigm also demonstrated an ability to improve regeneration after chronic denervation. ${ }^{27}$ We have previously injected lentiviral enhanced blue fluorescent protein (BFP) SCs into Thy-1 green fluorescent protein (GFP) rats that underwent doxorubicin-induced focal myelination. ${ }^{144}$ Our group showed that these cells may aid regeneration through growth factor production, ${ }^{27}$ debris clearance, ${ }^{145}$ and myelination ${ }^{144,146,147}$ (Figure 3).

In one experiment, SKP-SCs were impressively shown to improve behavioral recovery, even after acute transection repair. ${ }^{145}$ Skilled locomotor assessments such as ladder rung and tapered beam were seen to be improved in animals administered SKP-SCs after acute, chronic, and nerve graft repair. ${ }^{145}$ In addition, it was recently shown that SKP-SC action may in part involve their local immunomodulatory effect on both neurites and macrophages, which appears to be mediated by an interleukin-6-dependent mechanism. ${ }^{148}$ As a cell for translational therapy, SKP-SCs seem quite promising. Human SKP-SCs are able to be produced by differentiation of human-induced pluripotent stem cells, ${ }^{149}$ whereas the practical expansion of clinically relevant numbers of SKP$\mathrm{SC}$ s has been shown to be possible through the use of bioreactors. ${ }^{143}$

\section{2 | CURRENT STATE OF CLINICAL TRANSLATION}

In recent years we have seen tremendous progress in precursor and stem cell biology and its application in the treatment of various neurological disorders. Clinical trials in the United States have evaluated the regenerative benefits of stem cells in the context of multiple sclerosis (MS), amyotrophic lateral sclerosis (ALS), Alzheimer disease (AD), Duchenne muscular dystrophy (DMD), traumatic spinal cord injury, and other disorders of the nervous system. ${ }^{35,124,150}$ Unfortunately, there have been very few clinical trials examining the use of stem cells in the clinical treatment of peripheral nerve pathologies, ${ }^{151}$ and none specifically investigating the neuroregenerative benefits of stem cells after traumatic peripheral nerve injury. ${ }^{35}$

Although the neuroprotective and regenerative potential of stem cells in the repair of peripheral nerves has been demonstrated both in vitro and in vivo in a number of animal models, it is currently unclear when widespread clinical implementation of stem cell therapies will become a reality. Of note, no cell-based approach has shown clear superiority over another, and few preclinical studies have attempted to compare one cell type with another. ${ }^{152}$ The literature is also limited by the lack of data on the clinical safety and efficacy of stem cellderived therapies, with no long-term reports currently available. The clinical use and early promise of autologous SC therapies in clinical nerve repair ${ }^{153,154}$ suggest that cell types that can be readily predifferentiated in vitro to SCs (such as SKPs) or demonstrate transdifferentiation to $\mathrm{SCs}$ in vivo (such as BMSCs and ADSCs) may have the highest potential for clinical success. Levi and colleagues from the University of Miami recently detailed the first-in-human use of autologous SCs to supplement sciatic nerve repair. ${ }^{153,154}$ In these groundbreaking studies, two patients were enrolled in a US Food and Drug Administration-approved trial to assess both the safety and ability of autologous cultured SCs to enhance regeneration through sural nerve autografts. Long-term follow-up in both patients demonstrated nerve graft patency, absence of tumor formation, and significant improvements in both sensory and motor impairments compared with preoperative values. ${ }^{154}$

Although these initial clinical studies are encouraging, more rigorous studies examining stem cell stability, differentiation, and migration patterns are required before clinical safety is definitively established. ${ }^{155}$ Metrics that accurately characterize the clinical efficacy of stem cell-based therapies must also be identified. Current peripheral nerve stem cell literature exhibits wide variability in animal models, nerve injury type, stem cell source, differentiation protocols, cell-delivery methods, and assessment of nerve regeneration. In particular, variations in the timing of diverse outcome measures between different stem cell treatment modalities make specific treatments difficult to assess. ${ }^{35,37}$ These inconsistencies make it extremely difficult to establish clear conclusions about efficacy or safety in a clinical population. In addition, ethical considerations are a necessity when translating research from the bench to bedside. Furthermore, governmental restrictions and regulations may negatively affect the speed of translation of stem cell therapy into clinical practice. ${ }^{156-158}$ Strategies to manipulate cells using genetic and viral transduction approaches in vitro to potentially enhance their effect in vivo (as recently reviewed $^{159}$ ) raise additional regulatory considerations. Nevertheless, the evidence presented in this review suggests an promising future for stem cell-based approaches to traumatic peripheral nerve damage, although continued high-quality research is essential for bench-tobedside translation. Our opinion is that approaches that use stem and precursor cells akin to an SC phenotype have the greatest potential for clinical translation.

\section{3 | CONCLUSION}

Peripheral nerve injuries remain a common problem with unsatisfactory functional outcomes after standard therapeutic interventions. Several stem cell-based therapies have been investigated in both invitro and in-vivo experiments to positively modulate the regenerative milieu after nerve injury. These advancements suggest a promising future for stem cell-based approaches in enhancing regeneration and functional recovery after nerve injury.

\section{ETHICAL PUBLICATION STATEMENT}

We confirm that we have read the Journal's position on issues involved in ethical publication and affirm that this report is consistent with those guidelines. 


\section{REFERENCES}

1. Noble J, Munro CA, Prasad VS, Midha R. Analysis of upper and lower extremity peripheral nerve injuries in a population of patients with multiple injuries. J Trauma. 1998;45:116-122.

2. Pabari A, Yang SY, Seifalian AM, Mosahebi A. Modern surgical management of peripheral nerve gap. J Plast Reconstr Aesthet Surg. 2010; 63:1941-1948.

3. Millesi H. Progress in peripheral nerve reconstruction. World J Surg. 1990;14:733-747.

4. Brenner MJ, Hess JR, Myckatyn TM, Hayashi A, Hunter DA, Mackinnon SE. Repair of motor nerve gaps with sensory nerve inhibits regeneration in rats. Laryngoscope. 2006;116:1685-1692.

5. Grinsell D, Keating CP. Peripheral nerve reconstruction after injury: a review of clinical and experimental therapies. Biomed Res Int. 2014; 2014:698256.

6. Scholz T, Krichevsky A, Sumarto A, et al. Peripheral nerve injuries: an international survey of current treatments and future perspectives. J Reconstr Microsurg. 2009;25:339-344.

7. Kemp SW, Cederna PS, Midha R. Comparative outcome measures in peripheral regeneration studies. Exp Neurol. 2017;287:348-357.

8. Evans GR. Peripheral nerve injury: a review and approach to tissue engineered constructs. Anat Rec. 2001;263:396-404.

9. Sunderland S. The anatomy and physiology of nerve injury. Muscle Nerve. 1990;13:771-784.

10. Ren Z, Wang Y, Peng J, Zhao Q, Lu S. Role of stem cells in the regeneration and repair of peripheral nerves. Rev Neurosci. 2012;23:135-143.

11. Bosse F, Hasenpusch-Theil K, Kury P, Muller HW. Gene expression profiling reveals that peripheral nerve regeneration is a consequence of both novel injury-dependent and reactivated developmental processes. J Neurochem. 2006;96:1441-1457.

12. Navarro $X$, Vivo $M$, Valero-Cabre A. Neural plasticity after peripheral nerve injury and regeneration. Prog Neurobiol. 2007;82:163-201.

13. Saika T, Senba E, Noguchi $K$, et al. Effects of nerve crush and transection on mRNA levels for nerve growth factor receptor in the rat facial motoneurons. Brain Res Mol Brain Res. 1991;9:157-160.

14. Frostick SP, Yin Q, Kemp GJ. Schwann cells, neurotrophic factors and peripheral nerve regeneration. Microsurgery. 1998;18:397-405.

15. Hammarberg H, Piehl F, Cullheim S, Fjell J, Hokfelt T, Fried K. GDNF mRNA in Schwann cells and DRG satellite cells after chronic sciatic nerve injury. Neuroreport. 1996;7:857-860.

16. Mackinnon SE. New directions in peripheral nerve surgery. Ann Plast Surg. 1989;22:257-273.

17. Burnett MG, Zager EL. Pathophysiology of peripheral nerve injury: a brief review. Neurosurg Focus. 2004;16:E1.

18. Stoll G, Muller HW. Nerve injury, axonal degeneration and neural regeneration: basic insights. Brain Pathol. 1999;9:313-325.

19. Hadlock T, Sundback C, Hunter D, Cheney M, Vacanti JP. A polymer foam conduit seeded with Schwann cells promotes guided peripheral nerve regeneration. Tissue Eng. 2000;6:119-127.

20. Rodriguez FJ, Verdu E, Ceballos D, Navarro X. Nerve guides seeded with autologous Schwann cells improve nerve regeneration. Exp Neurol. 2000;161:571-584.

21. Ansselin AD, Fink T, Davey DF. Peripheral nerve regeneration through nerve guides seeded with adult Schwann cells. Neuropathol Appl Neurobiol. 1997;23:387-398.

22. Nishiura Y, Brandt J, Nilsson A, Kanje M, Dahlin LB. Addition of cultured Schwann cells to tendon autografts and freeze-thawed muscle grafts improves peripheral nerve regeneration. Tissue Eng. 2004;10: 157-164.

23. Kingham PJ, Mantovani C, Terenghi G. Notch independent signalling mediates Schwann cell-like differentiation of adipose derived stem cells. Neurosci Lett. 2009;467:164-168.

24. Mimura T, Dezawa M, Kanno H, Sawada H, Yamamoto I. Peripheral nerve regeneration by transplantation of bone marrow stromal cellderived Schwann cells in adult rats. J Neurosurg. 2004;101:806-812.
25. Wang Y, Zhao Z, Ren Z, et al. Recellularized nerve allografts with differentiated mesenchymal stem cells promote peripheral nerve regeneration. Neurosci Lett. 2012;514:96-101.

26. Dezawa M, Takahashi I, Esaki M, Takano M, Sawada H. Sciatic nerve regeneration in rats induced by transplantation of in vitro differentiated bone-marrow stromal cells. Eur J Neurosci. 2001;14:1771-1776.

27. Walsh SK, Gordon T, Addas BM, Kemp SW, Midha R. Skin-derived precursor cells enhance peripheral nerve regeneration following chronic denervation. Exp Neurol. 2010;223:221-228.

28. Schaakxs D, Kalbermatten DF, Raffoul W, Wiberg M, Kingham PJ. Regenerative cell injection in denervated muscle reduces atrophy and enhances recovery following nerve repair. Muscle Nerve. 2013; 47:691-701.

29. Mao Q, Nguyen PD, Shanti RM, et al. Gingiva-derived mesenchymal stem cell-extracellular vesicles activate Schwann cell repair phenotype and promote nerve regeneration. Tissue Eng Part A. 2019;25: 887-900.

30. Gotherstrom C, West A, Liden J, Uzunel M, Lahesmaa R, Le Blanc K. Difference in gene expression between human fetal liver and adult bone marrow mesenchymal stem cells. Haematologica. 2005;90:1017-1026.

31. Yan H, Hale J, Jaffray J, et al. Developmental differences between neonatal and adult human erythropoiesis. Am J Hematol. 2018;93: 494-503.

32. Fairbairn NG, Meppelink AM, Ng-Glazier J, Randolph MA, Winograd JM. Augmenting peripheral nerve regeneration using stem cells: a review of current opinion. World J Stem Cells. 2015;7:11-26.

33. Zack-Williams SD, Butler PE, Kalaskar DM. Current progress in use of adipose derived stem cells in peripheral nerve regeneration. World J Stem Cells. 2015;7:51-64.

34. Sayad Fathi S, Zaminy A. Stem cell therapy for nerve injury. World J Stem Cells. 2017;9:144-151.

35. De la Rosa MB, Kozik EM, Sakaguchi DS. Adult stem cell-based strategies for peripheral nerve regeneration. Adv Exp Med Biol. 2018; 1119:41-71.

36. $\mathrm{Yu} \mathrm{Z}, \mathrm{Xu} \mathrm{N}$, Zhang $\mathrm{N}$, et al. Repair of peripheral nerve sensory impairments via the transplantation of bone marrow neural tissuecommitted stem cell-derived sensory neurons. Cell Mol Neurobiol. 2019;39:341-353.

37. Yousefi F, Lavi Arab F, Nikkhah K, Amiri H, Mahmoudi M. Novel approaches using mesenchymal stem cells for curing peripheral nerve injuries. Life Sci. 2019;221:99-108.

38. Kingham PJ, Kalbermatten DF, Mahay D, Armstrong SJ, Wiberg M, Terenghi G. Adipose-derived stem cells differentiate into a Schwann cell phenotype and promote neurite outgrowth in vitro. Exp Neurol. 2007;207:267-274.

39. Arthur A, Rychkov G, Shi S, Koblar SA, Gronthos S. Adult human dental pulp stem cells differentiate toward functionally active neurons under appropriate environmental cues. Stem Cells. 2008;26: 1787-1795.

40. McKenzie IA, Biernaskie J, Toma JG, Midha R, Miller FD. Skinderived precursors generate myelinating Schwann cells for the injured and dysmyelinated nervous system. J Neurosci. 2006;26: 6651-6660.

41. Sowa Y, Imura T, Numajiri T, Nishino K, Fushiki S. Adipose-derived stem cells produce factors enhancing peripheral nerve regeneration: influence of age and anatomic site of origin. Stem Cells Dev. 2012; 21:1852-1862.

42. Lavasani M, Thompson SD, Pollett JB, et al. Human muscle-derived stem/progenitor cells promote functional murine peripheral nerve regeneration. J Clin Invest. 2014;124:1745-1756.

43. Cuevas $P$, Carceller F, Dujovny $M$, et al. Peripheral nerve regeneration by bone marrow stromal cells. Neurol Res. 2002;24:634-638.

44. Cuevas P, Carceller F, Garcia-Gomez I, Yan M, Dujovny M. Bone marrow stromal cell implantation for peripheral nerve repair. Neurol Res. 2004;26:230-232. 
45. Chen CJ, Ou YC, Liao SL, et al. Transplantation of bone marrow stromal cells for peripheral nerve repair. Exp Neurol. 2007;204:443-453.

46. Cheng FC, Sheu ML, Su HL, et al. The effect of exercise on mobilization of hematopoietic progenitor cells involved in the repair of sciatic nerve crush injury. J Neurosurg. 2013;118:594-605.

47. Mohammadi R, Vahabzadeh B, Amini K. Sciatic nerve regeneration induced by transplantation of in vitro bone marrow stromal cells into an inside-out artery graft in rat. J Craniomaxillofac Surg. 2014;42 1389-1396.

48. Zhao Z, Wang Y, Peng J, et al. Improvement in nerve regeneration through a decellularized nerve graft by supplementation with bone marrow stromal cells in fibrin. Cell Transplant. 2014;23:97-110.

49. Wang D, Liu XL, Zhu JK, et al. Bridging small-gap peripheral nerve defects using acellular nerve allograft implanted with autologous bone marrow stromal cells in primates. Brain Res. 2008;1188:44-53.

50. Wang D, Liu XL, Zhu JK, et al. Repairing large radial nerve defects by acellular nerve allografts seeded with autologous bone marrow stromal cells in a monkey model. J Neurotrauma. 2010;27:1935-1943.

51. Jia $\mathrm{H}, \mathrm{Wang} \mathrm{Y}$, Tong $\mathrm{XJ}$, et al. Sciatic nerve repair by acellular nerve xenografts implanted with BMSCs in rats xenograft combined with BMSCs. Synapse. 2012;66:256-269.

52. Nijhuis TH, Bodar CW, van Neck JW, et al. Natural conduits for bridging a 15-mm nerve defect: comparison of the vein supported by muscle and bone marrow stromal cells with a nerve autograft J Plast Reconstr Aesthet Surg. 2013;66:251-259.

53. Zarbakhsh S, Bakhtiyari M, Faghihi A, et al. The effects of Schwann and bone marrow stromal stem cells on sciatic nerve injury in rat: a comparison of functional recovery. Cell J. 2012;14:39-46.

54. Wang Y, Li ZW, Luo M, Li YJ, Zhang KQ. Biological conduits combining bone marrow mesenchymal stem cells and extracellular matrix to treat long-segment sciatic nerve defects. Neural Regen Res. 2015;10: 965-971.

55. Hu J, Zhu QT, Liu XL, Xu YB, Zhu JK. Repair of extended peripheral nerve lesions in rhesus monkeys using acellular allogenic nerve grafts implanted with autologous mesenchymal stem cells. Exp Neurol. 2007;204:658-666.

56. Akiyama Y, Radtke C, Honmou O, Kocsis JD. Remyelination of the spinal cord following intravenous delivery of bone marrow cells. Glia. 2002;39:229-236.

57. Zuk PA, Zhu M, Ashjian P, et al. Human adipose tissue is a source of multipotent stem cells. Mol Biol Cell. 2002;13:4279-4295.

58. Gimble JM, Katz AJ, Bunnell BA. Adipose-derived stem cells for regenerative medicine. Circ Res. 2007;100:1249-1260.

59. Walocko FM, Khouri RK Jr, Urbanchek MG, Levi B, Cederna PS. The potential roles for adipose tissue in peripheral nerve regeneration. Microsurgery. 2016;36:81-88.

60. Walocko FM, Eber AE, Kirsner RS, Badiavas E, Nouri K. Systematic review of the therapeutic roles of adipose tissue in dermatology. J Am Acad Dermatol. 2018;79:935-944.

61. Krug C, Beer A, Hartmann B, et al. Fibrin glue displays promising in vitro characteristics as a potential carrier of adipose progenitor cells for tissue regeneration. J Tissue Eng Regen Med. 2019;13: 359-368.

62. Tomita K, Madura T, Mantovani C, Terenghi G. Differentiated adipose-derived stem cells promote myelination and enhance functional recovery in a rat model of chronic denervation. J Neurosci Res. 2012;90:1392-1402.

63. di Summa PG, Kingham PJ, Raffoul W, Wiberg M, Terenghi G, Kalbermatten DF. Adipose-derived stem cells enhance peripheral nerve regeneration. J Plast Reconstr Aesthet Surg. 2010;63:1544-1552.

64. Liu G, Cheng Y, Guo S, et al. Transplantation of adipose-derived stem cells for peripheral nerve repair. Int J Mol Med. 2011;28: 565-572.

65. Marconi S, Castiglione G, Turano E, et al. Human adipose-derived mesenchymal stem cells systemically injected promote peripheral nerve regeneration in the mouse model of sciatic crush. Tissue Eng Part A. 2012;18:1264-1272.

66. Faroni A, Smith RJ, Lu L, Reid AJ. Human Schwann-like cells derived from adipose-derived mesenchymal stem cells rapidly dedifferentiate in the absence of stimulating medium. Eur J Neurosci. 2016;43:417-430.

67. Shortt AJ, Secker GA, Lomas RJ, et al. The effect of amniotic membrane preparation method on its ability to serve as a substrate for the ex-vivo expansion of limbal epithelial cells. Biomaterials. 2009; 30:1056-1065.

68. Wilshaw SP, Kearney J, Fisher J, Ingham E. Biocompatibility and potential of acellular human amniotic membrane to support the attachment and proliferation of allogeneic cells. Tissue Eng Part A. 2008;14:463-472.

69. Kronsteiner B, Peterbauer-Scherb A, Grillari-Voglauer R, et al. Human mesenchymal stem cells and renal tubular epithelial cells differentially influence monocyte-derived dendritic cell differentiation and maturation. Cell Immunol. 2011;267:30-38.

70. Kronsteiner B, Wolbank S, Peterbauer A, et al. Human mesenchymal stem cells from adipose tissue and amnion influence T-cells depending on stimulation method and presence of other immune cells. Stem Cells Dev. 2011;20:2115-2126.

71. Mligiliche N, Endo K, Okamoto K, Fujimoto E, Ide C. Extracellular matrix of human amnion manufactured into tubes as conduits for peripheral nerve regeneration. J Biomed Mater Res. 2002;63:591-600.

72. Banerjee A, Nurnberger S, Hennerbichler S, et al. In toto differentiation of human amniotic membrane towards the Schwann cell lineage. Cell Tissue Bank. 2014;15:227-239.

73. Li Y, Guo L, Ahn HS, Kim MH, Kim SW. Amniotic mesenchymal stem cells display neurovascular tropism and aid in the recovery of injured peripheral nerves. J Cell Mol Med. 2014;18:1028-1034.

74. Kim SW, Zhang HZ, Kim CE, Kim JM, Kim MH. Amniotic mesenchymal stem cells with robust chemotactic properties are effective in the treatment of a myocardial infarction model. Int J Cardiol. 2013; 168:1062-1069.

75. Bailo M, Soncini M, Vertua E, et al. Engraftment potential of human amnion and chorion cells derived from term placenta. Transplantation. 2004;78:1439-1448.

76. Cargnoni A, Gibelli L, Tosini A, et al. Transplantation of allogeneic and xenogeneic placenta-derived cells reduces bleomycin-induced lung fibrosis. Cell Transplant. 2009;18:405-422.

77. Gartner A, Pereira T, Alves MG, et al. Use of poly(DL-lactide-epsilon-caprolactone) membranes and mesenchymal stem cells from the Wharton's jelly of the umbilical cord for promoting nerve regeneration in axonotmesis: in vitro and in vivo analysis. Differentiation. 2012;84:355-365.

78. Gartner A, Pereira T, Simoes MJ, et al. Use of hybrid chitosan membranes and human mesenchymal stem cells from the Wharton jelly of umbilical cord for promoting nerve regeneration in an axonotmesis rat model. Neural Regen Res. 2012;7:2247-2258.

79. Divya MS, Roshin GE, Divya TS, et al. Umbilical cord blood-derived mesenchymal stem cells consist of a unique population of progenitors co-expressing mesenchymal stem cell and neuronal markers capable of instantaneous neuronal differentiation. Stem Cell Res Ther. 2012;3:57.

80. Hao L, Zhang C, Chen XH, et al. Human umbilical cord blood-derived stromal cells suppress xenogeneic immune cell response in vitro. Croat Med J. 2009;50:351-360.

81. Jablonska A, Kozlowska H, Markiewicz I, Domanska-Janik K, Lukomska B. Transplantation of neural stem cells derived from human cord blood to the brain of adult and neonatal rats. Acta Neurobiol Exp (Warsaw). 2010;70:337-350.

82. Sung MA, Jung HJ, Lee JW, et al. Human umbilical cord bloodderived mesenchymal stem cells promote regeneration of crushinjured rat sciatic nerves. Neural Regen Res. 2012;7:2018-2027. 
83. Zhao F, Qu Y, Liu H, Du B, Mu D. Umbilical cord blood mesenchymal stem cells co-modified by TERT and BDNF: a novel neuroprotective therapy for neonatal hypoxic-ischemic brain damage. Int J Dev Neurosci. 2014;38:147-154.

84. Hsieh JY, Wang HW, Chang SJ, et al. Mesenchymal stem cells from human umbilical cord express preferentially secreted factors related to neuroprotection, neurogenesis, and angiogenesis. PLoS One. 2013;8:e72604.

85. Pan Y, Jiao G, Yang J, Guo R, Li J, Wang C. Insights into the therapeutic potential of heparinized collagen scaffolds loading human umbilical cord mesenchymal stem cells and nerve growth factor for the repair of recurrent laryngeal nerve injury. Tissue Eng Regen Med. 2017;14:317-326.

86. Chen M, Xiang Z, Cai J. The anti-apoptotic and neuro-protective effects of human umbilical cord blood mesenchymal stem cells (hUCB-MSCs) on acute optic nerve injury is transient. Brain Res. 2013;1532:63-75.

87. Zhu JQ, Lu HK, Cui ZQ, et al. Therapeutic potential of human umbilical cord blood mesenchymal stem cells on erectile function in rats with cavernous nerve injury. Biotechnol Lett. 2015;37:1515-1525.

88. Song L, Zhu J, Zhang X, et al. BDNF-hypersecreting human umbilical cord blood mesenchymal stem cells promote erectile function in a rat model of cavernous nerve electrocautery injury. Int Urol Nephrol. 2016;48:37-45.

89. Zhang ZJ, Li YJ, Liu XG, et al. Human umbilical cord blood stem cells and brain-derived neurotrophic factor for optic nerve injury: a biomechanical evaluation. Neural Regen Res. 2015;10:1134-1138.

90. Spagnuolo G, Codispoti B, Marrelli M, Rengo C, Rengo S, Tatullo M. Commitment of oral-derived stem cells in dental and maxillofacial applications. Dent J (Basel). 2018;6(4).

91. Al-Zer H, Apel C, Heiland M, et al. Enrichment and Schwann cell differentiation of neural crest-derived dental pulp stem cells. In Vivo. 2015;29:319-326.

92. Al-Zer $\mathrm{H}$, Kalbouneh $\mathrm{H}$. Dental pulp stem cells-derived Schwann cells for peripheral nerve injury regeneration. Neural Regen Res. 2015;10:1945-1946.

93. Ullah I, Subbarao RB, Kim EJ, et al. In vitro comparative analysis of human dental stem cells from a single donor and its neuronal differentiation potential evaluated by electrophysiology. Life Sci. 2016;154:39-51.

94. Mead B, Logan A, Berry M, Leadbeater W, Scheven BA. concise review: dental pulp stem cells: a novel cell therapy for retinal and central nervous system repair. Stem Cells. 2017;35:61-67.

95. Gronthos S, Mankani M, Brahim J, Robey PG, Shi S. Postnatal human dental pulp stem cells (DPSCs) in vitro and in vivo. Proc Natl Acad Sci USA. 2000;97:13625-13630.

96. Gronthos S, Brahim J, Li W, et al. Stem cell properties of human dental pulp stem cells. J Dent Res. 2002;81:531-535.

97. Huang GT, Gronthos S, Shi S. Mesenchymal stem cells derived from dental tissues vs. those from other sources: their biology and role in regenerative medicine. J Dent Res. 2009;88:792-806.

98. Iohara K, Zheng L, Ito M, Tomokiyo A, Matsushita K, Nakashima M. Side population cells isolated from porcine dental pulp tissue with self-renewal and multipotency for dentinogenesis, chondrogenesis, adipogenesis, and neurogenesis. Stem Cells. 2006;24:2493-2503.

99. Yang R, Chen M, Lee CH, Yoon R, Lal S, Mao JJ. Clones of ectopic stem cells in the regeneration of muscle defects in vivo. PLoS One. 2010;5:e13547.

100. Reynolds AJ, Jahoda CA. Cultured human and rat tooth papilla cells induce hair follicle regeneration and fiber growth. Differentiation. 2004;72:566-575.

101. Ishkitiev N, Yaegaki K, Calenic B, et al. Deciduous and permanent dental pulp mesenchymal cells acquire hepatic morphologic and functional features in vitro. J Endod. 2010;36:469-474.

102. Morsczeck C. Cellular senescence in dental pulp stem cells. Arch Oral Biol. 2019;99:150-155.
103. Mead B, Logan A, Berry $M$, Leadbeater W, Scheven BA. Intravitreally transplanted dental pulp stem cells promote neuroprotection and axon regeneration of retinal ganglion cells after optic nerve injury. Invest Ophthalmol Vis Sci. 2013;54:7544-7556.

104. Martens W, Sanen K, Georgiou M, et al. Human dental pulp stem cells can differentiate into Schwann cells and promote and guide neurite outgrowth in an aligned tissue-engineered collagen construct in vitro. FASEB J. 2014;28:1634-1643.

105. Carnevale G, Pisciotta A, Riccio M, et al. Human dental pulp stem cells expressing STRO-1, c-kit and CD34 markers in peripheral nerve regeneration. J Tissue Eng Regen Med. 2018;12:e774-e785.

106. Ullah I, Choe YH, Khan M, et al. Dental pulp-derived stem cells can counterbalance peripheral nerve injury-induced oxidative stress and supraspinal neuro-inflammation in rat brain. Sci Rep. 2018;8:15795.

107. Hei WH, Kim S, Park JC, et al. Schwann-like cells differentiated from human dental pulp stem cells combined with a pulsed electromagnetic field can improve peripheral nerve regeneration. Bioelectromagnetics. 2016;37:163-174.

108. Castiglioni A, Hettmer S, Lynes MD, et al. Isolation of progenitors that exhibit myogenic/osteogenic bipotency in vitro by fluorescence-activated cell sorting from human fetal muscle. Stem Cell Rep. 2014;2:92-106.

109. Pisani DF, Dechesne CA, Sacconi S, et al. Isolation of a highly myogenic CD34-negative subset of human skeletal muscle cells free of adipogenic potential. Stem Cells. 2010;28:753-764.

110. Charville GW, Cheung TH, Yoo B, et al. Ex vivo expansion and in vivo self-renewal of human muscle stem cells. Stem Cell Rep. 2015;5:621-632.

111. Tamaki T, Okada Y, Uchiyama Y, et al. Clonal multipotency of skeletal muscle-derived stem cells between mesodermal and ectodermal lineage. Stem Cells. 2007;25:2283-2290.

112. Zhu Q, Lu Q, Gao R, Cao T. Prospect of human pluripotent stem cell-derived neural crest stem cells in clinical application. Stem Cells Int. 2016;2016:7695836.

113. Tamaki T, Hirata M, Nakajima N, et al. A long-gap peripheral nerve injury therapy using human skeletal muscle-derived stem cells (SkSCs): an achievement of significant morphological, numerical and functional recovery. PLoS One. 2016;11:e0166639.

114. Mombaerts $P$, Wang F, Dulac $C$, et al. Visualizing an olfactory sensory map. Cell. 1996;87:675-686.

115. Boruch AV, Conners JJ, Pipitone M, et al. Neurotrophic and migratory properties of an olfactory ensheathing cell line. Glia. 2001;33:225-229.

116. Nazareth L, Tello Velasquez J, Lineburg KE, Chehrehasa F, St John JA, Ekberg JA. Differing phagocytic capacities of accessory and main olfactory ensheathing cells and the implication for olfactory glia transplantation therapies. Mol Cell Neurosci. 2015;65:92-101.

117. Panni P, Ferguson IA, Beacham I, Mackay-Sim A, Ekberg JA, St John JA. Phagocytosis of bacteria by olfactory ensheathing cells and Schwann cells. Neurosci Lett. 2013;539:65-70.

118. Deng C, Gorrie C, Hayward I, et al. Survival and migration of human and rat olfactory ensheathing cells in intact and injured spinal cord. J Neurosci Res. 2006;83:1201-1212.

119. Gorrie CA, Hayward I, Cameron N, et al. Effects of human OECderived cell transplants in rodent spinal cord contusion injury. Brain Res. 2010;1337:8-20.

120. Li BC, Li Y, Chen LF, Chang JY, Duan ZX. Olfactory ensheathing cells can reduce the tissue loss but not the cavity formation in contused spinal cord of rats. J Neurol Sci. 2011;303:67-74.

121. Ramer LM, Au E, Richter MW, Liu J, Tetzlaff W, Roskams AJ. Peripheral olfactory ensheathing cells reduce scar and cavity formation and promote regeneration after spinal cord injury. J Comp Neurol. 2004;473:1-15.

122. Li Y, Decherchi P, Raisman G. Transplantation of olfactory ensheathing cells into spinal cord lesions restores breathing and climbing. J Neurosci. 2003;23:727-731. 
123. Granger N, Blamires H, Franklin RJ, Jeffery ND. Autologous olfactory mucosal cell transplants in clinical spinal cord injury: a randomized double-blinded trial in a canine translational model. Brain. 2012; 135:3227-3237.

124. Tabakow P, Jarmundowicz W, Czapiga B, et al. Transplantation of autologous olfactory ensheathing cells in complete human spinal cord injury. Cell Transplant. 2013;22:1591-1612.

125. Dombrowski MA, Sasaki M, Lankford KL, Kocsis JD, Radtke C. Myelination and nodal formation of regenerated peripheral nerve fibers following transplantation of acutely prepared olfactory ensheathing cells. Brain Res. 2006;1125:1-8.

126. Penna V, Stark GB, Wewetzer K, Radtke C, Lang EM. Comparison of Schwann cells and olfactory ensheathing cells for peripheral nerve gap bridging. Cells Tissues Organs. 2012;196:534-542.

127. Hoffman RM. Nestin-expressing hair follicle-accessible pluripotent stem cells for nerve and spinal cord repair. Cells Tissues Organs. 2014;200:42-47.

128. Hoffman RM. Introduction to hair-follicle-associated pluripotent stem cells. Methods Mol Biol. 2016;1453:1-5.

129. Amoh Y, Kanoh M, Niiyama S, et al. Human and mouse hair follicles contain both multipotent and monopotent stem cells. Cell Cycle. 2009;8:176-177.

130. Sieber-Blum M, Grim M, Hu YF, Szeder V. Pluripotent neural crest stem cells in the adult hair follicle. Dev Dyn. 2004;231:258-269.

131. Yashiro M, Mii S, Aki R, et al. From hair to heart: nestin-expressing hair-follicle-associated pluripotent (HAP) stem cells differentiate to beating cardiac muscle cells. Cell Cycle. 2015;14:2362-2366.

132. Yamazaki A, Obara $\mathrm{K}$, Tohgi $\mathrm{N}$, et al. Implanted hair-follicleassociated pluripotent (HAP) stem cells encapsulated in polyvinylidene fluoride membrane cylinders promote effective recovery of peripheral nerve injury. Cell Cycle. 2017;16:1927-1932.

133. Biernaskie J, Paris M, Morozova O, et al. SKPs derive from hair follicle precursors and exhibit properties of adult dermal stem cells. Cell Stem Cell. 2009;5:610-623.

134. Amoh Y, Katsuoka K, Hoffman RM. Peripheral-nerve and spinal-cord regeneration in mice using hair-follicle-associated pluripotent (HAP) stem cells. Methods Mol Biol. 2016;1453:21-32.

135. Serbedzija GN, Fraser SE, Bronner-Fraser M. Pathways of trunk neural crest cell migration in the mouse embryo as revealed by vital dye labelling. Development. 1990;108:605-612.

136. Baggiolini A, Varum S, Mateos JM, et al. Premigratory and migratory neural crest cells are multipotent in vivo. Cell Stem Cell. 2015;16: 314-322.

137. Achilleos A, Trainor PA. Neural crest stem cells: discovery, properties and potential for therapy. Cell Res. 2012;22:288-304.

138. Jones I, Novikova LN, Novikov LN, et al. Regenerative effects of human embryonic stem cell-derived neural crest cells for treatment of peripheral nerve injury. J Tissue Eng Regen Med. 2018;285:e2099-e2109.

139. Cui L, Jiang J, Wei L, et al. Transplantation of embryonic stem cells improves nerve repair and functional recovery after severe sciatic nerve axotomy in rats. Stem Cells. 2008;26:1356-1365.

140. Toma JG, McKenzie IA, Bagli D, Miller FD. Isolation and characterization of multipotent skin-derived precursors from human skin. Stem Cells. 2005;23:727-737.

141. Walsh S, Midha R. Use of stem cells to augment nerve injury repair. Neurosurgery. 2009;65(suppl):A80-A86.

142. Walsh S, Biernaskie J, Kemp SW, Midha R. Supplementation of acellular nerve grafts with skin derived precursor cells promotes peripheral nerve regeneration. Neuroscience. 2009;164:1097-1107.

143. Walsh T, Biernaskie J, Midha R, Kallos MS. Bioreactor expansion of skinderived precursor Schwann cells. Methods Mol Biol. 2016;1502:103-110.
144. Grochmal J, Teo W, Gambhir H, et al. A novel approach to 32-channel peripheral nervous system myelin imaging in vivo, with single axon resolution. J Neurosurg. 2018;130:163-171.

145. Khuong HT, Kumar R, Senjaya F, et al. Skin derived precursor Schwann cells improve behavioral recovery for acute and delayed nerve repair. Exp Neurol. 2014;254:168-179.

146. Grochmal J, Dhaliwal S, Stys PK, van Minnen J, Midha R. Skinderived precursor Schwann cell myelination capacity in focal tibial demyelination. Muscle Nerve. 2014;50:262-272.

147. Kumar R, Sinha S, Hagner A, et al. Adult skin-derived precursor Schwann cells exhibit superior myelination and regeneration supportive properties compared to chronically denervated nervederived Schwann cells. Exp Neurol. 2016;278:127-142.

148. Stratton JA, Shah PT, Kumar R, et al. The immunomodulatory properties of adult skin-derived precursor Schwann cells: implications for peripheral nerve injury therapy. Eur J Neurosci. 2016;43: 365-375.

149. Sugiyama-Nakagiri Y, Fujimura T, Moriwaki S. Induction of skinderived precursor cells from human induced pluripotent stem cells. PLoS One. 2016;11:e0168451.

150. Squillaro T, Peluso G, Galderisi U. Clinical trials with mesenchymal stem cells: an update. Cell Transplant. 2016;25:829-848.

151. Li XY, Zheng ZH, Li XY, et al. Treatment of foot disease in patients with type 2 diabetes mellitus using human umbilical cord blood mesenchymal stem cells: response and correction of immunological anomalies. Curr Pharm Des. 2013;19:4893-4899.

152. Gonzalez-Perez F, Hernandez J, Heimann C, Phillips JB, Udina E, Navarro X. Schwann cells and mesenchymal stem cells in laminin- or fibronectin-aligned matrices and regeneration across a critical size defect of $15 \mathrm{~mm}$ in the rat sciatic nerve. J Neurosurg Spine. 2018;28: 109-118.

153. Levi AD, Burks SS, Anderson KD, Dididze M, Khan A, Dietrich WD. The use of autologous schwann cells to supplement sciatic nerve repair with a large gap: first in human experience. Cell Transplant. 2016;25:1395-1403.

154. Gersey ZC, Burks SS, Anderson KD, et al. First human experience with autologous Schwann cells to supplement sciatic nerve repair: report of 2 cases with long-term follow-up. Neurosurg Focus. 2017; 42:E2.

155. Csete M. Translational prospects for human induced pluripotent stem cells. Regen Med. 2010;5:509-519.

156. Campbell A, Nycum G. Harmonizing the international regulation of embryonic stem cell research: possibilities, promises and potential pitfalls. Med Law Int. 2005;7:113-148.

157. Kim JH, Alderton A, Crook JM, et al. A Report from a Workshop of the International Stem Cell Banking Initiative, held in collaboration of Global Alliance for iPSC Therapies and the Harvard Stem Cell Institute, Boston, 2017. Stem Cells. 2019;37:1130-1135.

158. Sipp D, Caulfield T, Kaye J, et al. Marketing of unproven stem cellbased interventions: a call to action. Sci Transl Med. 2017;9(397).

159. Mathot F, Shin AY, Van Wijnen AJ. Targeted stimulation of MSCs in peripheral nerve repair. Gene. 2019;710:17-23.

How to cite this article: Kubiak CA, Grochmal J, Kung TA, Cederna PS, Midha R, Kemp SWP. Stem-cell-based therapies to enhance peripheral nerve regeneration. Muscle Nerve. 2020; 61:449-459. https://doi.org/10.1002/mus.26760 